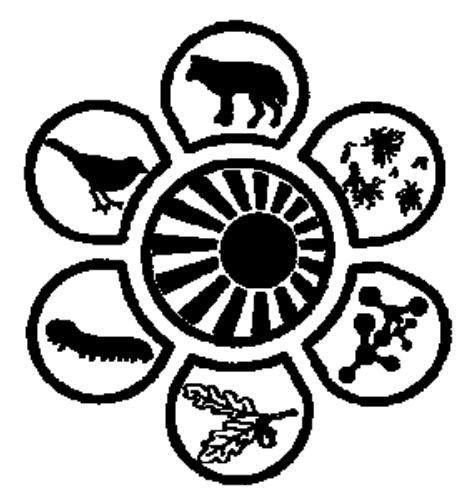

Вісник Дніпропетровського університету. Біологія, екологія.

Vìsnik Dnìpropetrovs'kogo unìversitetu. Seriâ Bìologiâ, ekologiâ

Visnyk of Dnipropetrovsk University. Biology, ecology.

Vìsn. Dnìpropetr. Unìv. Ser. Bìol. Ekol. 2014. 22(1), 46-52.

doi:10.15421/011406

ISSN 2310-0842 print

ISSN 2312-301X online

www.ecology.dp.ua

\title{
УДК 577.3+57.033 \\ Роль ферментов катаболизма АМР в энергетическом статусе эритроцитов в условиях их истощения по глюкозе
}

\author{
О.И. Доценко, Я.А. Трощинская
}

Донецкий наџиональный университет, Донеик, Украина

Изучено изменение активностей ферментов катаболизма АМР эритроцитов мембраносвязанной (еN) и цитоплазматической (cN-1A) форм 5'-нуклеотидазы, АМР-дезаминазы в условиях истощения по глюкозе и при действии на клетки вибрации в диапазоне 8-32 Гц (с шагом 4 Гц) амплитудой $0,5 \pm 0,04$ мм. На основании экспериментальных данных проанализированы механизмы регуляции метаболизма аденилатов в эритроцитах человека и принципы взаимодействия метаболизма аденилатов и энергетического метаболизма клетки. Активность мембраносвязанной 5'-нуклеотидазы может отражать перестройки липидного бислоя клетки при действии на нее внешних факторов.

Ключевые слова: эритроциты; вибрация; 5'-нуклеотидаза; АМР-дезаминаза; аденилатный метаболизм

\section{Role of AMP catabolism enzymes in the energetic status of erythrocytes under conditions of glucose depletion}

\author{
O.I. Dotsenko, Y.A. Troshchynskaya \\ Donetsk National University, Donetsk, Ukraine
}

The adenylate metabolism determines the value of energy charge, adenylate pool and ATP concentration, with its level strongly differing in various cell types. The reasons of such differences are still not clear, moreover, role of adenylate metabolism in the regulation of intracellular ATP concentration is not fully known. Hypotheses about mechanisms of adenylate pool stabilization are based on results of mathematical modeling and require the experimental verification. It is known that AMP catabolism enzymes such as AMP-desaminase and 5'-nucleotidase are directly involved in the processes of adenylate charge and pool regulation and their activity depends on the concentration of this metabolite. It is considered that switching from AMP-desaminase pathway of AMP catabolism to 5'-nucleotidase pathway and vice versa may contribute to stabilization of adenylate charge and pool under increased energy load that leads to the reduction of ATP content. The objective of this study consisted in the experimental investigation of mechanisms of adenylate metabolism regulation in human erythrocytes as well as principles of adenylate and energy metabolism interaction in erythrocytes with varied energy charge. Changes in activities of catabolism enzymes such as AMP-membrane-bound (eN) and cytosolic (cN-IA) 5'-nucleotidase, AMP-desaminase (AMPDA) of erythrocytes under conditions of glucose depletion and under vibration effect on cells in the range of frequencies of 8-32 Hz, step of $4 \mathrm{~Hz}$, and the amplitude of $0,5 \pm 0,04 \mathrm{~mm}$ have been studied. Antiphase change of cN-IA and AMPDA activities in erythrocytes incubated in the medium without glucose was shown. Processes of switching of two ways of AMP catabolism create the conditions for the stabilization of energy charge and the ATP concentration stabilization though at a level below the initial one. In the erythrocytes in the medium without glucose and under vibration the antiphase change of enzyme activity was observed only under vibration at frequencies of 8 and $12 \mathrm{~Hz}$. Under action of vibration in the range of frequencies 16-28 Hz, AMP catabolism mainly occurred in AMPDA pathway, cN-II, which was evidenced by sigmoid character of increase in AMPDA activity more than 2 times. Under vibration at frequency of $16 \mathrm{~Hz}$ cN-IA activity insignificantly changed. In frequency range of 20-28 Hz cN-IA activity was growing monotonically during 3 hours of action. Growth of cN-IA activity $(50.0 \pm 4.5,34.3 \pm 12.8$, $39.1 \pm 1.8 \%$ under the action at frequencies of 20,24 and $32 \mathrm{~Hz}$ respectively, more than 2 times under action at $28 \mathrm{~Hz}$ ) proves that cN-IA, ADODA pathway is also involved in the processes of AMP catabolism. The AMPDA activity also increased under vibration at frequency of $32 \mathrm{~Hz}$, but the sigmoid character of the increase in activity was not observed. Thus, the processes of AMP catabolism intensify in erythrocytes under vibration. These processes are realized by two degradation ways. In this case, other mechanisms which are discussed in this study

Донеикий наииональный университет, ул. Щорса, 46, Донеик, 83050, Украина.

Donetsk National University, vul. Shersa, 46, Donetsk, 83050, Ukraine.

Tel.:+38-093-724-66-10.E-mail:dots_don@ukr.net 
are likely to be involved in the stabilization of AMP level. It was shown that membrane-bound 5'-nucleotidase activity could reflect the cell lipid bilayer reorganization under the influence of external factors.

Keywords: erythrocytes; vibration; 5'-nucleotidase; AMP-desaminase; adenylate metabolism

\section{Введение}

В настоящее время достигнут значительный прогресс в понимании регуляции клеточного метаболизма. В то же время, механизмы взаимодействия многих важных метаболических систем в клетке остаются не ясными. Это относится даже к такому важному внутриклеточному параметру как концентрация аденозин 5'-трифосфата (АТР). Концентрация АТР устанавливается в результате взаимодействия энергетического метаболизма и метаболизма аденилатов. Энергетический метаболизм обеспечивает взаимопревращение между АТР, аденозин 5'дифосфатом (ADP) и аденозин 5'-монофосфатом (AMP), определяя энергетический заряд клетки (АТР + $0,5 \mathrm{ADP}) /(\mathrm{ATP}+\mathrm{ADP}+\mathrm{AMP})$ и размер аденилатного пула (ATP + ADP + AMP) (Ataullakhanov and Vitvitsky, 2002; Dudzinska et al., 2006; Khlyntseva et al., 2009). Энергетический заряд клетки жестко контролируется метаболическими процессами (Chapman and Atkinson, 1973; Dudzinska et al., 2010; Walther et al., 2010; Plaideau et al., 2012; Dudzinska, 2014), уровень же АТР может существенно варьировать даже в клетках одного типа (Ataullakhanov and Vitvitsky, 2002).

Согласно гипотезе Аткинсона (Atkinson, 1968; Chapman and Atkinson, 1973), клетка стабилизирует свой энергетический заряд, используя следующий механизм. C ростом концентрации AMP энергетический заряд клетки снижается. Усиление процессов деградации АМР приводит к стабилизации энергетического заряда, уменьшая при этом размер аденилатного пула. Деградация (катаболизм) АМР происходит в двух реакциях. Одна из них - АМР-дезаминазная реакция, в которой аминогруппа безвозвратно отщепляется от АМР, приводя к образованию инозин 5'-монофосфата и аммиака. Во второй, катализируемой 5'-нуклеотидазой (5'-НТ), гидролитическое отщепление фосфатной группы приводит к образованию аденозина. Стабилизирующийся эффект очевиден, но цена за эту дополнительную стабилизацию - сокращение размера пула аденилатов и абсолютной концентрации АТР.

Экспериментальные данные свидетельствуют также о том, что сокращение энергетического заряда не обязательно подразумевает сопутствующее сокращение размера пула аденилатов. Его расширение может также наблюдаться (Ataullakhanov and Vitvitsky, 2002; Cheng, 2012; Dotsenko et al., 2013; Dudzinska, 2014). В этом случае неясно, как отрегулирован аденилатный метаболизм и связано ли увеличение содержания АТР с работой только аденилатного цикла. Атауллахановым (Ataullakhanov and Vitvitsky, 2002) высказана гипотеза о том, что уменьшение энергетического заряда, вследствие увеличенного энергопотребления, регулирует активности ферментов так, что потоки из синтеза AMP переключаются на потоки его деградации. Высокие концентрации АМР активируют АМР-дезаминазу, обладающую очень высокой активностью. Запускаемые процессы дезаминирования АМР позволяют быстро стабилизи- ровать энергетический заряд, однако аденилатный пул будет снижен. При низких концентрациях АМР активна 5'-НТ, однако ее активность на два порядка ниже АМРдезаминазы (Martinov et al., 2000; Plaideau et al., 2012). Переключение на 5'-НТ путь деградации АМР и снижение скорости катаболизма позволяет стабилизировать аденилатный пул. Детали этого процесса автор не оговаривает, возможно, это происходит с участием аденилаткиназной и аденозинкиназной реакций.

Необходимо учесть, что эритроциты являются уникальными среди тканей и клеток человека, потому что они не содержат достаточно аденилосукцинат синтетазы для поддержания измеримого анаболического потока от инозинмонофосфата (IMP) к аденозинмонофосфату. Непосредственным метаболическим следствием является неспособность синтезировать адениннуклеотиды de novo (Sabina et al., 2009). Несмотря на наличие ферментов ресинтеза АМР непосредственно из аденозина и аденина, циркулирующие уровни обоих соединений, как правило, являются довольно низкими, т. е. $<1$ мкМ. Следовательно, эритроциты имеют строго ограниченные возможности для поддержания пула адениновых нуклеотидов и связанных с ними энергетических запасов клетки. Это особенно очевидно в условиях энергетического дисбаланса, в результате усиления процессов использования АТР, что может привести к активации ферментов катаболизма и ускоренной потере адениннуклеотидов.

S. Schuster (Schuster and Kenanov, 2005) предложил еще один механизм стабилизации уровня АТР. Изучая пути ресинтеза АТР в эритроцитах путем расчета элементарных способов потока, выяснили, что накопление продуктов деградации АМР (аденозина, ионозинмонофосфата и инозина) способствует возвращению потока в пентозофосфатный путь и частично в путь Эмбдена Мейергофа, в результате чего эритроцит может дополнительно синтезировать АТР и D23PG.

Таким образом, механизмы, ответственные за процессы восстановления величины аденилатного пула и вклад в эти процессы метаболизма аденилатов, до конца не ясны. Представляет также интерес исследование механизма катаболизма AMP в условиях увеличенной энергетической нагрузки, а именно при истощении по глюкозе и дополнительном внешнем воздействии.

Цель работы состояла в экспериментальном исследовании механизмов регуляции метаболизма аденилатов в эритроцитах человека, принципов взаимодействия аденилатного и энергетического метаболизма в эритроцитах с измененным энергетическим зарядом.

\section{Материал и методы исследований}

В экспериментах использовали свежую кровь доноров примерно одной возрастной группы и одного пола. Эритроциты осаждали центрифугированием, после чего их 4-кратно отмывали от плазмы Трис- $\mathrm{HCl}$ (0,05 M, $p H 7,4)$, содержащим $0,15 \mathrm{M} \mathrm{NaCl}$ (буферный раствор 1). 
После центрифугирования удаляли надосадочную жидкость и белый опалесцирующий слой лейкоцитов, располагающийся над осадком эритроцитов. Полученная паста эритроцитов использовалась для приготовления суспензии, с содержанием гемоглобина 0,9 $\pm 0,06$ мг/мл. В качестве среды инкубирования использовали буферный раствор 1. Суспензию эритроцитов подвергали действию низкочастотной вибрации в интервале частот 832 Гц, с шагом 4 Гц амплитудой $0,5 \pm 0,04$ мм в течение 3 часов. Вибрацию совершали при помощи вибростенда, состоящего из генератора низкочастотных сигналов синусоидальной формы, усилителя и вибратора, совершающего колебания в вертикальной плоскости с заданной частотой и амплитудой. Экспериментальную кювету, заполненную суспензией эритроцитов, вертикально закрепляли на подвижной части вибратора (в этом случае механические колебания передаются в экспериментальную кювету с незначительными потерями мощности). Активность мембраносвязанной (eN) и цитоплазматической (cN-IA) форм 5'-НТ исследовали в тенях и в гемолизатах эритроцитов соответственно, активность AMP-дезаминазы (AMPDA) - в гемолизатах до начала эксперимента и затем каждые 20 мин в процессе вибрационного воздействия. В качестве контроля использовали активности изучаемых ферментов до начала эксперимента. Отдельно изучали влияние среды инкубирования на динамику изменения активностей этих же ферментов.

Активности eN и cN-IA изучали с помощью реакции гидролиза AMP с последующим определением неорганического фосфата (Pi) (Rozhkovskij and Kresjun, 1991). Активности ферментов выражали в мкM Pi, образующегося в течение 1 мин, отнесенных к количеству белка в пробе (мкМ/мин·г белка). Активность AMPDA определяли кинетическим спектрофотометрическим методом, основанным на регистрации накопления IMP в реакции дезаминирования. Оптическую плотность измеряли при 285 нм автоматически в течение 10 мин, шаг регистрации - 1 с. Для расчета активности фермента использовали наклон полученной линейной зависимости и разность экстинций для AMP и IMP, равную 0,3 (Lushchak and
Storey, 1994). Активность AMPDA выражали в мкМ/мин г белка.

Содержание гемоглобина в эритроцитарной пасте определяли гемиглобинцианидным унифицированным методом по стандартным наборам.

При построении зависимостей, приводимых ниже, использовались усредненные данные. Статистический анализ полученных результатов проводили в программе Statistica. Достоверность различий между среднегрупповыми показателями оценивали с помощью непараметрического рангового критерия Уилкоксона.

\section{Результаты и их обсуждение}

Процессы катаболизма АMP контролируют два цитоплазматических фермента AMPDA и 5'-HT (cN-IA), изменение активностей которых в эритроцитах, инкубируемых в среде, не содержащей глюкозы в течение 3 часов, показано на рисунке 1. Известно, что эритроциты, помещенные в среду, не содержащую глюкозу, быстро истощаются по АТР, и через некоторое время в клетках устанавливается новый стационарный уровень АТР, намного ниже исходного. Ранее нами было показано (Dotsenko et al., 2013), что инкубирование эритроцитов в среде такого же состава в течение 3 часов приводит к падению уровня АТР на 28-30\%, росту концентрации неорганического фосфата (Pi) в 3,0-3,2 раза относительно начального уровня. Эта информация согласуется с данными, полученными другими авторами, изучавшими метаболизм эритроцитов в режиме их истощения по глюкозе, несмотря на то, что состав среды инкубирования мог отличаться. По данным работы (Bontemps et al., 1986), уровень АМР при 4-часовом инкубировании эритроцитов в режиме истощения по глюкозе возрастает в 30 раз, в то время как ADP - в 2,5 раза. При таких условиях происходит падение энергетического заряда в эритроцитах и появление дисбаланса в соотношении адениннуклеотидов. Рост концентрации АМР, являющегося субстратом для AMPDA и 5'-HT, может быть причиной для усиления процессов катаболизма.

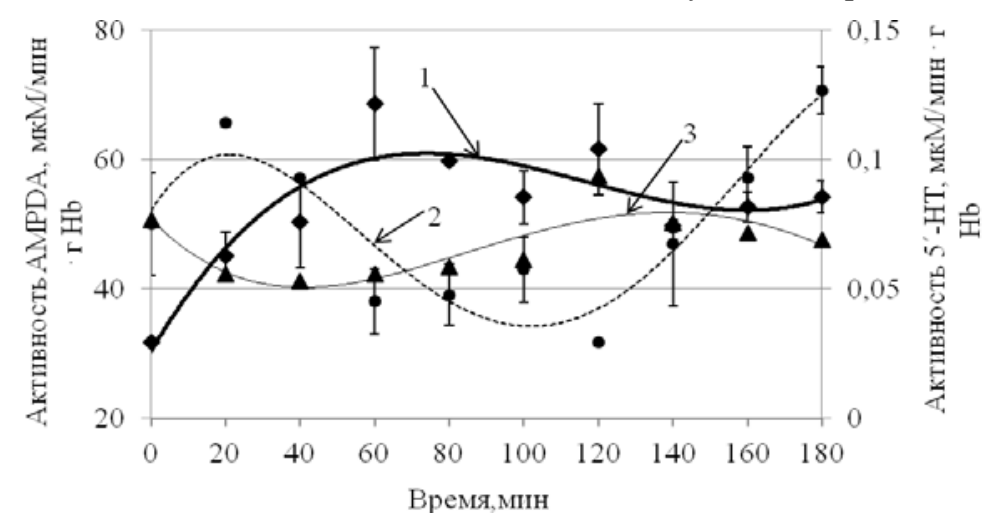

Рис. 1. Изменение активностей мембраносвязанной и цитоплазматической форм 5'-HT, AMPDA эритроцитов (мкМ/мин·г Нb) при их инкубировании в среде, не содержащей глюкозы:

1 - AMPDA, 2 - cN-IA, 3 - eN; среда инкубирования - Трис- $\mathrm{HCl} 0,05 \mathrm{M}, \mathrm{pH} 7,4$, содержащий $0,15 \mathrm{M} \mathrm{NaCl}$

Согласно литературным данным (Bontemps et al., 1986), в условиях истощения по глюкозе, $75 \%$ потока катаболизма AMP идет по пути 5'-HT, ADO-дезаминаза. В условиях эксперимента увеличение активности 5'-НТ в 1,2-1,5 раза фиксировали только в течение 40 мин ин- кубирования, после чего активность этого фермента существенно снижалась (рис. 1). В течение второго часа инкубирования активность 5'-НТ устанавливалась на уровне ниже начального на 40-60\%. В это время катаболизм AMP переключался на путь AMPDA, IMP-аза 
(cN-II), о чем свидетельствует рост активности AMPDA в 1,9-2,2 раза. Полученные нами данные согласуются с результатами экспериментов других авторов, которые также наблюдали фазовый характер изменений активностей ферментов катаболизма АМР, в частности, 5'-НТ (Kudina et al., 2003). Высокие концентрации AMP активируют AMPDA (сигмоидная зависимость реакции от концентрации AMP известна из литературы (Lian and Harkness, 1974; Sasaki et al., 1976; Ogasawara et al., 1986; Mosharov et al., 1998) и инактивируют 5'-HT. In vitro активность цитоплазматической 5'-HT (cN-IA) из очищенной печени крысы показала колоколообразную зависимость от энергетического заряда (Itoh, 1981; Martinov et al., 2000). Сродство этого фермента к AMP определялось энергетическим состоянием клетки и существенно возрастало в случае снижения аденилатного энергетического заряда до определенного уровня.

В течение третьего часа инкубирования активность AMPDA снижалась, однако оставалась выше контрольного уровня в $1,64 \pm 0,07$ раза (см. рис. 1). На снижение активности этого фермента может существенно влиять неорганический фосфат (Mosharov et al., 1998; Dudzinska et al., 2010), содержание которого к этому моменту увеличивалось более чем в 3 раза (Dotsenko et al., 2013). Кроме того, наблюдалась активация 5'-нуклеотидазы, активность которой через три часа воздействия возрастала в 1,6 раза. Процессы переключения двух способов катаболизма AMP создают условия для восстановления энергетического заряда и стабилизации концентрации ATP, хотя и на уровне ниже начального.

Ранее нами был показан разный характер изменения содержания АТР в эритроцитах в зависимости от частоты вибрационного воздействия. Вибрационное воздействие частотного интервала 8-16 Гц приводило к снижению АТР до определенного стационарного уровня. При действии вибрации интервала 20-28 Гц концентрация АТР снижалась в начале эксперимента, однако восстанавливалась до начальной величины к концу воздействия. При вибрационном воздействии с частотой 32 Гц концентрация АТР возрастала в течение эксперимента до уровня, более чем в 2 раза превышающего начальный. Представляло интерес проследить, связан ли прирост содержания АТР с особенностями функционирования цикла адениновых нуклеотидов.

На рисунках 2 и 3 показано изменение активностей AMPDA и цитоплазматической 5'-НТ эритроцитов, подвергавшихся вибрационному воздействию в изучаемом диапазоне частот. Явление перекрестной активности АМР-дезаминазы и цитоплазматической 5'-НТ зафиксировано только при действии вибрации в интервале частот 8-12 Гц. При вибрационном воздействии с частотой 8 Гц (рис. 2 a), через 60-80 мин вибрационного воздействия наблюдали снижение активности АМР-дезаминазы на 18 $24 \%$. Прирост активности 5'-НТ в 1,7 раза наблюдали через 20 мин воздействия. Дальнейшее вибрационное воздействие привело к росту активности АМР-дезаминазы и снижению активности 5'-НТ. Через 140 мин воздействия активность АМР-дезаминазы была максимальной и в 1,4 раза превышала уровень контроля. Через 160 мин наблюдали снижение активности АМР-дезаминазы и увеличение активности 5'-НТ (рис. 2 a), которое составило $36,5 \pm 12,7 \%$ относительно начального уровня.
При вибрационном воздействии в интервале частот 12-16 Гц снижение уровня АТР после трехчасового воздействия составило 20,0 $\pm 8,9 \%$ (12 Гц) и $12,0 \pm 3,7 \%$ (16 Гц) относительно начального уровня (Dotsenko et al., 2013). На рисунке 2 б показано изменение активности изучаемых ферментов при воздействии с частотой 16 Гц. В этом случае не обнаружено существенных изменений активности цитоплазматической формы 5'-НТ (колебания активности в процессе воздействия составили 10\% от исходного уровня). Катаболизм АМР осуществлялся AMPDA, активность которой возрастала в 2 раза после 20 мин воздействия и в 2,9 раза через 140 мин.

При вибрационном воздействии в интервале частот 20-28 Гц получили похожие изменения активностей AMPDA и 5'-HT (cN-IA). Во всех случаях наблюдали сигмоидную зависимость активности AMPDA, которая достигала максимальных значений во временном интервале 60-80 мин (увеличение активности в $1,56 \pm 0,20$ раза при воздействии с частотой 20 Гц, $1,40 \pm 0,12$ раза 24 Гц, 1,85 \pm 0,05 раза - 28 Гц). К концу эксперимента активность AMPDA снижалась (в наибольшей степени при вибрации с частотой 24 Гц) (рис. $3 a$ ). На этом фоне фиксировали монотонный рост активности цитоплазматической формы 5'-НТ, который к концу эксперимента составил 50,0 \pm 4,5\% при воздействии 20 Гц, 34,3 \pm $12,8 \%$ - при воздействии 24 Гц, более $100 \%$ - при воздействии 28 Гц (рис. $3 a$ ).

При вибрационном воздействии с частотой 32 Гц рост активности AMPDA (40-45\%) фиксировали только к концу эксперимента. При этом активация 5'-НТ составила в конце эксперимента $35,0 \pm 2,3 \%$ (рис. 3 б).

Незначительный прирост активностей ферментов катаболизма AMP (особенно cN-IA) в эритроцитах, подвергавшихся вибрационному воздействию, свидетельствует о том, что в регулировании концентрации АТР задействованы также и другие механизмы, тесно связанные с работой этих ферментов. Возможность дополнительного синтеза АТР за счет возврата потока из цикла метаболизма пуринов в гликолитический путь нами не рассматривалась из-за отсутствия аденозина в среде инкубирования (Kim, 1990; Komarova et al., 1999; Dudzinska et al., 2010) и незначительной активации cN-IA. Единственным средством восстановления концентрации АТР в эритроцитах, истощенных по глюкозе и подвергающихся дополнительному воздействию, является активация АМР-киназы (АМРК), являющейся высококонсервативным энергетическим сенсором (Föller et al., 2009). АМРК активируется изменением внутриклеточного соотношения АMP/ATP (Plaideau, 2012). ADP и AMP, аденилатный заряд клетки являются важными физиологическими медиаторами активности AMPК (Oakhill et al., 2011, 2012). Таким образом, ингибирование АМР метаболизирующих ферментов может быть средством активации АМРК в клетках. В работе (Plaideau et al., 2012) показано, что именно снижение активности cN-IA важно для активации этого фермента. После активации АМРК фосфорилирует несколько метаболических целей, что приводит к снижению потребления АТР. Падение активности $N a-K$-зависимой АТРазы в эритроцитах, подвергавшихся вибрации 20-32 Гц в среде без глюкозы, показано ранее. Инактивация $N a-K$-зависимой АТРазы в эритроцитах при вибрационном воздействии 32 Гц составила более $80 \%$ (Dotsenko et al., 2013). 


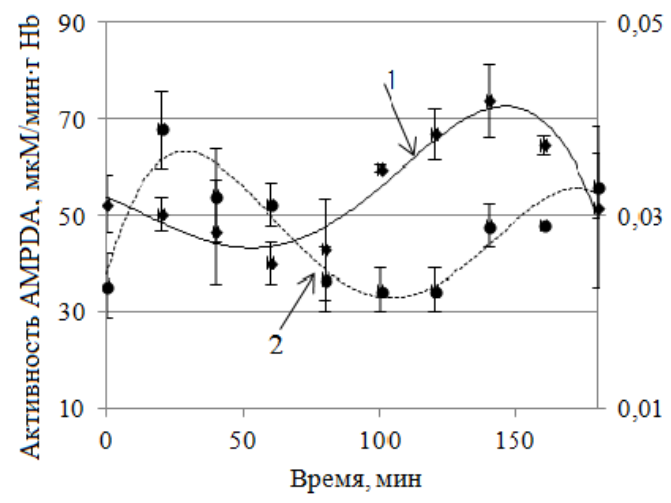

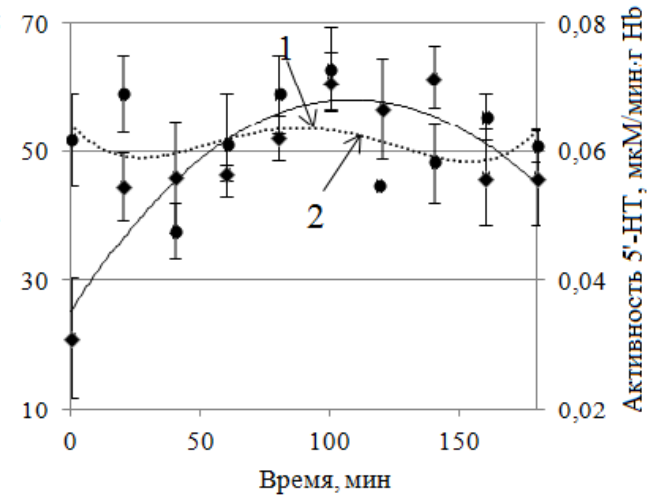

$\sigma$

Рис. 2. Изменение активностей ферментов катаболизма АМР (мкМ/мин·г Нb)

при действии вибрации на суспензию эритроцитов: $a$ - вибрационное воздействие с частотой 8 Гц, $\sigma$ - с частотой 16 Гц, амплитуда $0,5 \pm 0,04$ мм; 1 - AMPDA, $2-\mathrm{cN}-\mathrm{IA}$

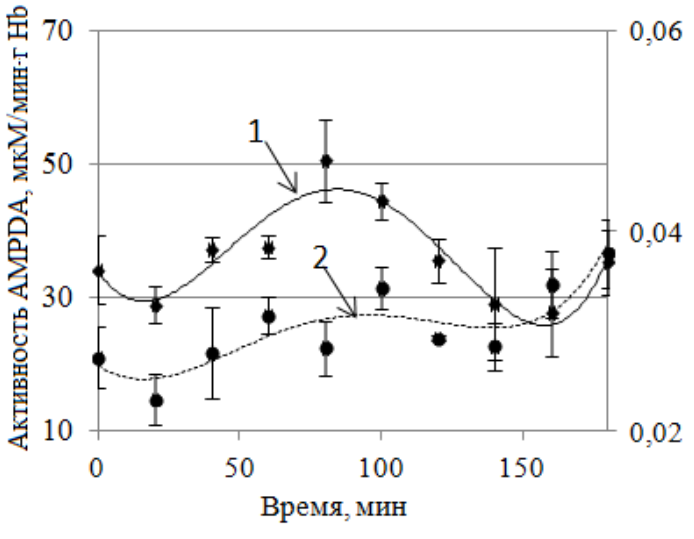

$a$

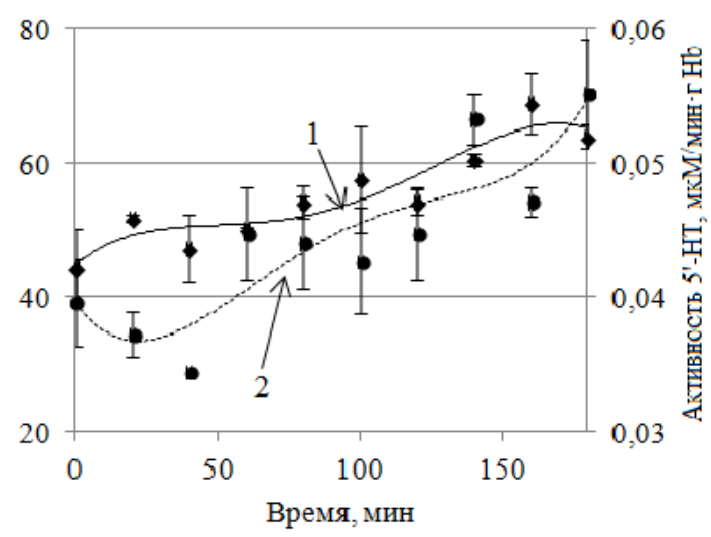

$\sigma$

Рис. 3. Изменение активностей ферментов катаболизма АМР (мкМ/мин·г Нb)

при действии вибрации на суспензию эритроцитов: $a$ - вибрационное воздействие с частотой 24 Гц, $\sigma$ - с частотой 32 Гц, амплитуда $0,50 \pm 0,04$ мм; 1 - AMPDA, $2-\mathrm{cN}-\mathrm{IA}$

Мембраносвязанная форма 5'-нуклеотидазы (eN) связывается с липидным бислоем клетки через гликозилфосфатидилинозитол (ГФИ-якорь) и это взаимодействие существенно влияет на активность фермента (Bianchi and Spychala, 2003; Pexa and Deussen, 2005; Colgan et al., 2006; Fujita and Jigami, 2008; Bogan and Brenner, 2010). Данные работы (Danylova et al., 2003) свидетельствуют о том, что этот фермент является маркером мембранных рафтов - сфинголипидхолестероловых микродоменов, характеризующихся специфическим липидным и белковым составом и включающихся в большое число клеточных функций. Индивидуальные, неассоциированные рафты представляют собой относительно небольшие структуры, содержащие не больше нескольких десятков белковых молекул (Pralle et al., 2000). Высказана гипотеза, что индивидуальные рафты не способны поддерживать высокий уровень активности ассоциированных с ними сигнальных молекул и только вследствие их ассоциации в большие структуры этот уровень может превышать порог, необходимый для возникновения стабильного сигнала (Yegutkin, 2008; Knapp et al., 2012). Взаимодействие eN с рафтами мембраны дает возможность рассматривать свойства этого фермен- та в более широком аспекте. Изменение активности мембраносвязанной формы 5'-НТ в экспериментах без действия вибрации показано на рисунке 1. Видно, что активность еN уменьшалась через 40 минут на 59,2 \pm $8,2 \%$ относительно начального уровня и удерживалась на этом уровне в течение 100 мин эксперимента. Дальнейшее инкубирование эритроцитов в среде без глюкозы приводило к восстановлению активности фермента до уровня контроля. На рисунке 4 показано изменение $\mathrm{eN}$ в эритроцитах, подвергавшихся действию вибрации.

Активный центр экто-5'-НТ расположен снаружи и обращен в среду инкубирования. Осутствие субстрата (АМР) в среде инкубирования должно приводить к инактивации фермента (Реха and Deussen, 2005). Эти процессы наблюдаются в начале эксперимента как без вибрационного воздействия, так и при действии вибрации. Затем во временном интервале 60-120 мин фиксировали рост активности еN (рис. 4). Такое повышение активности может быть связано с перестройкой липидного бислоя и ассоциацией рафтов. Процессы, косвенно свидетельствующие о перестройке липидного бислоя эритроцитов, подвергающихся действию вибрации в среде без глюкозы, наблюдались нами ранеe (Dotsenko et al., 2012, 2013). 


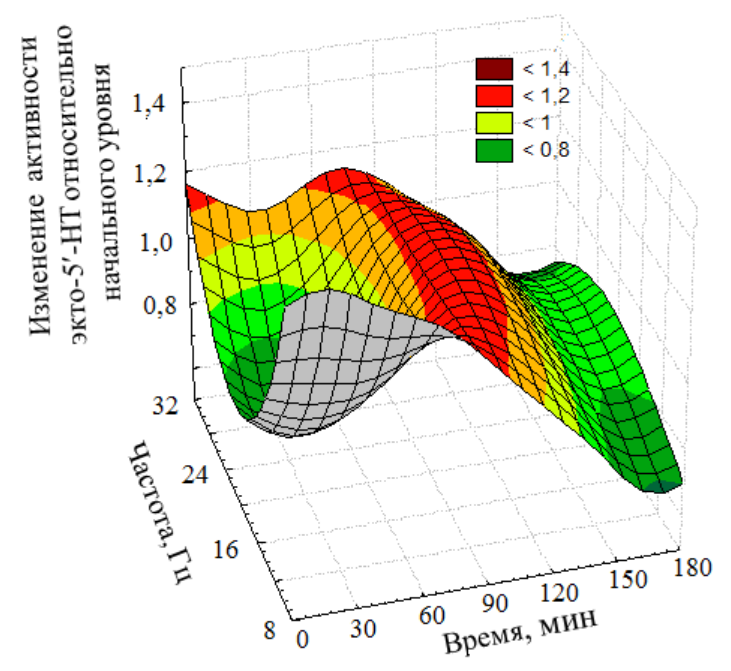

Рис. 4. Частотно-временная зависимость изменения активности экто-5'-нуклеотидазы относительно начального уровня

Дальнейшее снижение активности еN может быть связано с повреждением ГФИ-якоря, вызванного перестройкой липидного бислоя или повреждением мембраны (Fujita and Jigami, 2008, Kopylchuk et al., 2009), либо с той же причиной - отсутствием субстрата в среде инкубирования. Таким образом, фиксируемое увеличение активности eN можно рассматривать как маркер перестройки липидного бислоя эритроцитов под действием внешнего фактора.

\section{Выводы}

Экспериментально показано, что процессы переключения двух способов катаболизма АМР создают условия для восстановления энергетического заряда и стабилизации концентрации АТР, хотя и на уровне ниже начального. Незначительный прирост активностей ферментов катаболизма AMP, особенно cN-IA, в эритроцитах, истощенных по глюкозе и подвергающихся дополнительной нагрузке (вибрационному воздействию), свидетельствует о том, что в регулировании концентрации АТР задействованы также другие механизмы, тесно связанные с работой этих ферментов. Активность экто-5'-НТ можно рассматривать как маркер перестройки липидного бислоя эритроцитов под действием внешнего фактора.

\section{Библиографические ссылки}

Ataullakhanov, F.I., Vitvitsky, V.M., 2002. What determines the intracellular ATP concentration. Biosci. Rep. 22(5), 501511.

Atkinson, D.E., 1968. The energy charge of the adenylate pool as a regulatory parameter. Interaction with feedback modifiers. Biochem. 7(11), 4030-4034.

Baranowska-Bosiacka, I., Hlynczak, A.J., Wiszniewska, B., Marchlewic, M., 2004. Disorders of purine metabolism in human erythrocytes in the state of lead contamination. Pol. J. Environ. Stud. 13(5), 467-476.

Bianchi, V., Spychala, J., 2003. Mammalian 5'-nucleotidases (minireview). J. Biol. Chem. 278(47), 46195-46198.
Bogan, K.L., Brenner, C., 2010. 5'-nucleotidases and their new roles in $\mathrm{NAD}^{+}$and phosphate metabolism. New J. Chem. 34, 845-853.

Bontemps, F., Van den Berghe, G., Hers, H.G., 1986. Pathways of adenine nucleotide catabolism in erythrocytes. J. Clin. Invest. 77, 824-830.

Chapman, A.G., Atkinson, D.E., 1973. Stabilization of adenylate energy charge by the adenylatedeaminase reaction. J. Biol. Chem. 248, 8309-8312.

Cheng, J., Morisaki, H., Toyama, K., Ikawa, M., Okabe, M., Morisaki, T., 2012. AMPD3-deficient mice exhibit increased erythrocyte ATP levels but anemia not improved due to PK deficiency. Genes Cells 17(11), 913-922.

Colgan, S.P., Eltzschig, H.K., Eckle, T., Thompson, L.F., 2006. Physiological roles for ecto-5'-nucleotidase (CD73). Purinergic Signal. 2, 351-360.

Danylova, V.M., Andruhova, O.V., Babijchuk, V.S., 2003. Katalitychni vlastyvosti 5'-nukleotydazy u skladi membrannyh raftiv klityn gladen'kyh m'jaziv [Catalytic properties of 5'-nucleotidase within membrane rafts of smooth muscle cells]. Ukrainian Journal of Biochemistry 75(3), 71-76 (in Ukrainian).

Dotsenko, O.I. Troshchynskaya, Y.A., Konyukhova, N.R., 2012. Izuchenie processov obrazovanija membranosvjazannogo gemoglobina $\mathrm{v}$ jeritrocitah pod dejstviem nizkochastotnoj vibracii [Studying of processes of formation of membranebound hemoglobin in erythrocytes under the influence of low-frequency vibration]. Problems of Ecology and Nature Protection of Techogen Region 12, 274-280 (in Russian).

Dotsenko, O.I., Konyukhova, N.R., Troshchynskaya, Y.A., 2013. Reguljacija strukturnogo stanu bilkiv cytoskeletu erytrocytiv pry dii' na nyh nyz'kochastotnoi' vibracii' [Regulation of erythrocytes cytoskeleton proteins structural state at low-frequency vibration action]. Visnyk Donec'kogo Nacional'nogo Universytetu. Ser. A: Pryrodnychi Nauky 1, 149-156 (in Ukrainian).

Dudzinska, W., 2014. Purine nucleotides and their metabolites in patients with type 1 and 2 diabetes mellitus. J. Biomed. Sci. Eng. 7, 38-44.

Dudzinska, W., Hlynczak, A.J., Skotnicka, E., Suska, M., 2006. The purine metabolism of human erythrocytes. Biochemistry (Moscow) 71(5), 467-475.

Dudzinska, W., Lubkowska, A., Dolegowska, B., Safranow, K., Jakubowska, K., 2010. Adenine, guanine and pyridine nucleotides in blood during physical exercise and restitution in healthy subjects. Eur. J. Appl. Physiol. 110, 1155-1162.

Föller, M., Sopjani, M., Koka, S., Gu, S., Mahmud, H., Wang, K., Floride, E., Schleicher, E., Schulz, E., Münzel, T., Lang, F., 2009. Regulation of erythrocyte survival by AMP-activated protein kinase. FASEB J. 23(4), 1072-1080.

Fujita, M., Jigami, Y., 2008. Lipid remodeling of GPI-anchored proteins and its function. Biochim. Biophys. Acta 1780(3), 410-420.

Hardie, D.G., Ashford, M.L.J., 2014. AMPK: Regulating energy balance at the cellular and whole body levels. Physiology 29, 99-107.

Itoh, R., 1981. Regulation of cytosol 5'-nucleotidase by adenylate energy charge. Biochim. Biophys. Acta 659, 31-37.

Khlyntseva, S.V., Vishnikin, A.B., Bazel', Y.R., Andruch, V., 2009. Methods for the determination of adenosine triphosphate and other adenine nucleotides. J. Analyt. Chem. 64(7), 657-673.

Kim, H.D., 1990. Is adenosine a second metabolic substrate for human red blood cells. Biochim. Biophys. Acta 1036, 113 120.

Knapp, K., Zebisch, M., Pippel, J., EI-Tayeb, A., Müller, C.E., Sträter, N., 2012. Crystal structure of the human ecto-5'nucleotidase (CD73): Insights into the regulation of purinergic signaling. Cell Press 20(12), 2161-2173. 
Komarova, S., Mosharov, E.V., Vitvitskii, V., Ataullakhanov, F.I., 1999. Adenine nucleotide synthesis in human erythrocytes depends on the mode of supplementation of cell suspension with adenosine. Blood Cells Mol. Dis. 25, 170-179.

Kopylchuk, Y.P., Buchkovska, I.M., Voloschuk, O.M., 2009. 5'Nukleotydazna ta AMR-dezaminazna aktyvnosti postnuklearnoi' frakcii' pechenky ta syrovatky krovi shhuriv iz transplantovanoju karcynomoju gerena [5'-Nucleotidase and AMP-deaminase activities of liver postnuclear fraction and blood serium of rats with transplanted Guerin's carcinoma]. Stud. Biol. 3(3), 69-74 (in Ukrainian).

Kudina, N.G., Andriychyk, T.R., Tsudzevich, B.O., 2003. Aktyvnist' fermentiv purynovogo obminu $\mathrm{v}$ tymocytah shhuriv za promenevogo urazhennja ta vvedennja i'm ryboksynu [Purine metabolism enzymes activity in rat's thymocytes after irradiation and after the riboxine injection]. Ukrainian Journal of Biochemistry 75(2), 109-112 (in Ukrainian).

Lian, C.-Y., Harkness, D.R., 1974. The kinetic properties of adenylate deaminase from human erythrocytes. Biochim. Biophys. Acta. 341, 27-40.

Lushchak, V.I., Storey, K.B., 1994. Effect of exercise on the properties of AMP-deaminase from trout white muscle. Int. J. Biochem. 26(10), 1305-1312.

Martinov, M.V., Plotnikov, A.G., Vitvitsky, V.M., Ataullakhanov, F.I., 2000. Deficiencies of glycolytic enzymes as a possible cause of hemolytic anemia. Biochim. Biophys. Acta 1474(1), 75-87.

Mosharov, E.V, Vitvitsky, V.M., Ataullakhanow, F.I., 1998. Product activation of human erythrocyte AMP deaminase. FEBS Lett 440, 64-66.

Oakhill, J.S., Scott, J.W., Kemp, B.E., 2012. AMPK functions as an adenylate charge-regulated protein kinase. Trends Endocrin. Met. 23(3), 125-132.

Oakhill, J.S., Steel, R., Chen, Z.P., Scott, J.W., Ling, N., Tam, S., Kemp, B.E., 2011. AMPK is a direct adenylate chargeregulated protein kinase. Science 332, 1433-1435.

Ogasawara, N., Goto, H., Yamada, Y., Hasegawa, I., 1986. Deficiency of erythrocyte type isozyme of AMP deaminase in human. Adv. Exp. Med. Biol. 195A, 123-127.
Pexa, A., Deussen A., 2005. Modulation of ecto-5'-nucleotidase by phospholipids in human umbilical vein endothelial cells (HUVEC). Naunyn Schmiedebergs Arch. Pharmacol. 372, 131-138.

Plaideau, C., Liu, J., Hartleib-Geschwindner, J., Bastin-Coyette, L., Bontemps, F., Oscarsson, J., Hue, L., Rider, M.H., 2012. Overexpression of AMP-metabolizing enzymes controls adenine nucleotide levels and AMPK activation in HEK293T cells. FASEB J. 26, 2685-2694.

Pralle, A., Keller, P., Florin, E.-L., Simons, K., Hörber, K.H., 2000. Sphingolipid-cholesterol rafts diffuse as small entities in the plasma membrane of mammalian cells. J. Cell. Biol. 148(5), 997-1008.

Rozhkovskij, J.V., Kresjun, V.I., 1991. Aktivnost' markernyh fermentov i sostojanie lipidnogo matriksa membran jeritrocitov pri stresse i ego medikamentoznoj korrekcii [The activity of marker enzymes and the state of the lipid matrix of membranes of red blood cells under stress and its medical correction]. Ukrainian Journal of Biochemistry 63(4), 74-80 (in Russian).

Sabina, R.L., Wandersee, N.J., Hillery, C.A., 2009. Br. J. Haematol., 144(3), 434-445.

Sasaki, R., Ikura, K., Ciba, H., 1976. Regulation of human erythrocyte AMP deaminase by ATP and 2,3-bisphosphoglycerate. Agr. Biol. Chem. 40, 1797-1803.

Schuster, S., Kenanov, D., 2005. Adenine and adenosine salvage pathways in erythrocytes and the role of S-adenosylhomocysteine hydrolase. A theoretical study using elementary flux modes. FEBS J. 272, 5278-5290.

Walther, T., Novo, M., Rössger, K., Létisse, F., Loret, M.O., Portais, J.C., François, J.M., 2010. Control of ATP homeostasis during the respiro-fermentative transition in yeast. Mol. Syst. Biol. 6, 344 .

Yegutkin, G.G., 2008. Nucleotide- and nucleoside-converting ectoenzymes: Important modulators of purinergetic signalling cascade. Biochim. Biophys. Acta 1783, 673-694.

Надійшла до редколегії 21.04.2014 